\title{
Enhancing Research Mechanisms and Institutional Processes in Malaysia: A Case Study of Universiti Malaya (UM)
}

\author{
Azrin Md Kasim ${ }^{1, \#}$, Lee Wei Chang ${ }^{2,3, \#}$, Nuratiqah Mohamad Norpi ${ }^{4, \#, *}$, \\ Noor Hayaty Abu Kasim ${ }^{5}$ Azirah Hashim ${ }^{6}$ \\ ${ }^{1}$ Research Data Management Unit (RDMU), Level 7, Research Management \& Innovation Complex, University of \\ Malaya, 50603 Kuala Lumpur, Malaysia \\ ${ }^{2}$ Centre for Research Services (PPP), Level 2, Research Management \& Innovation Complex University of Malaya, \\ 50603 Kuala Lumpur, Malaysia \\ ${ }^{3}$ Centre for Civilisational Dialogue, Level 1, Door C6, High Impact Research Building, University of Malaya, 50603 \\ Kuala Lumpur, Malaysia \\ ${ }^{3}$ Centre for Research Grant Management (PPGP), Level 4, Research Management \& Innovation Complex, University \\ of Malaya, 50603 Kuala Lumpur, Malaysia. \\ ${ }^{5}$ Faculty of Dentistry, Universiti Kebangsaan Malaysia, Jalan Raja Muda Abdul Aziz, 50300 Kuala Lumpur, Malaysia \\ ${ }^{6}$ Department of English Language, Faculty of Languages \& Linguistics, University of Malaya, 50603 Kuala Lumpur, \\ Malaysia \\ \# These authors contributed equally: Azrin Md Kasim, Lee Wei Chang, Nuratiqah Mohamad Norpi
}

"Corresponding author email:

tqanorpi@um.edu.my

Received date: 23 Jul 2021

Published date: 31 Dec 2021

How to cite:

Md Kasim, A., Chang, L.W., Mohamad Norpi, N., Abu Kasim, N.H. \& Hashim, A. (2021). Enhancing Research Mechanisms and Institutional Processes in Malaysia: A Case Study of Universiti Malaya (UM). Journal of Research Management \& Governance, 4(1), 10-23. Retrieved from https:// ejournal.um.edu.my/index.php/ JRMG/article/view/31338

DOI:

https://doi.org/10.22452/ jrmg.vol4no1.2

\section{ABSTRACT}

Malaysia's research and development landscape has grown tremendously over the last decade. The growth of scholarly output in Malaysia has also risen significantly compared to countries such as China, Singapore and Australia. Malaysia has made it a target that research output and quality will increase through an expenditure of $1.3 \%$ of the GDP allocated to Research and Development (R\&D). Thus far, Malaysia has achieved phenomenal growth within the research sector, with a four-fold increase in the number of citations and has generated approximately RM1.25 billion through $11 \%$ yearly growth in the number of patents from Malaysian Universities. This case study aims to provide, firstly, an overview of research governance in Malaysia, and secondly, a discussion of research governance practices at Universiti Malaya (UM). Data is obtained from the 11th Malaysian Plan (2016-2020) and linked to the Malaysian Transformation Program. The Malaysian Education Blueprint for Higher Education (2015-2025) launched in 2015 also outlined a comprehensive transformation for research in higher education programmes. In addition, other published documents on research governance practices by agencies providing research funding were also reviewed. This case study highlights best practices in research management and governance to strengthen and further enhance the current research management and governance in support of the Malaysian government's initiative towards achieving a high-income nation status.

Keywords: Research Governance; Research Mechanisms; Best Practice; University; Research Ecosystem 


\section{Introduction}

The Universiti Malaya (UM), Malaysia's oldest university, was established in Singapore in 1949 when the King Edward VII College of Medicine (founded in 1905) merged with Raffles College (founded in 1928). Its 890-acre campus is strategically located within the heart of Kuala Lumpur, making it ideal for international students and visiting academics. UM is the premier multidisciplinary research university in Malaysia with more than 28,000 students and 2,000 academic staff. There are 14 faculties, 2 academies, 4 research clusters and more than 75 research centres in the disciplines of Medicine, Engineering, Sciences, Arts and Humanities. UM's alumni of over 200,000 have amongst them renowned and illustrious Malaysian personalities and leaders. UM, ranked 59th in the QS World University Rankings 2021, is the first choice of Malaysia's top students and more than 3,800 international students from over 80 countries. The university's strength lies in the creativity, talent and dynamism of its people built on its illustrious history (Universiti Malaya, 2021a).

As a research university, UM focuses on developing strategies to benefit from the new global environment. UM has been, and remains, at the forefront of landmark scientific and medical discoveries as is evidenced by the numerous awards that have been won both locally and internationally (Universiti Malaya, 2021a). UM researchers are in collaborative partnerships with various institutions at national and international level and internationally working on diverse topics from HIV-AIDS, infectious diseases, biodiversity, nanotechnology to law, intellectual property, culture, religion, gender studies and poverty eradication studies (Universiti Malaya, 2021b). In the coming years, the university is projected to have a further quantum leap in high-quality research activity and publications as a result of the huge research funding being channeled to the university from numerous sources and the strive for excellence among students and staff.

UM researchers involved in research development have long-term experience in strengthening the research capacity of partner institutions via the increasing bilateral partnerships or the signing of MoU/ MoA (Universiti Malaya, 2021b). This support is provided through human resource development (curriculum development), exchange of expertise and experience between institutions, support of research methodology and equipment, student exchange, field-based interdisciplinary, intercultural courses and through strengthening of the partner institutions participation in international scientific networks in this region. As a university in the Association of Southeast Asian Nations(ASEAN), a region that has committed itself to the goals and aspirations of the ASEAN Community Vision 2025, intraregional cooperation is important to UM. The ASEAN University Network (AUN), of which UM is a member, has goals for strengthening and promoting educational and research cooperation in the region. Therefore, education and research have become one of the focal points in capacity building and UM has been involved in capacity building activities since 2011 under Malaysia's Global Outreach Programme (Azirah Hashim et al., 2018). This programme is part of the internationalisation initiatives by the Ministry of Higher Education, Malaysia which also strives to contribute towards narrowing the development gap among member states in ASEAN.

Following the success of UM's collaboration and engagement in capacity building activities, including research seminars, teaching workshops, and curriculum development, collaboration in research capacity building for novice researchers both in the Science, Technology and Innovation (STI) and Non-STI, a 
similar international capacity building programme initiated by UM researchers was recognized and supported by a UM research grant (2015-2017) (Azirah Hashim et al., 2018). This case study fits in with what UM has been doing which is to develop human capital and facilitate individual learning and institutional mechanisms in STI and Non-STI research in higher education institutions in Malaysia through research training and capacity building, including research governance, leading to sustainable highquality research, conditions for cooperation and potential for policy impact.

This case study aims to give an overview of the research governance in Malaysia. In addition, information on research governance practised at UM is also described. Information on Malaysia's research focus and initiatives was gathered from the 11th Malaysian Plan (2016-2020) and linked to the Malaysian Transformation Program. The Malaysian Education Blueprint for Higher Education (2015-2025) launched in 2015 also outlined a comprehensive transformation for research in higher education programmes. Other published documents were also reviewed on research governance practised by agencies providing research funding. Through this case study, best practices in research management and governance to strengthen and further enhance the current research management and governance in UM to support the Malaysian government's initiative towards achieving a high-income nation status are highlighted.

The report aims at highlighting the research initiatives and implementation of research governance practices as stated in the Malaysia's policies and strategic plans, explains the processes in research management in Malaysia taking UM as a case study, highlights challenges faced in research governance and puts forwards some proposals for changes needed to further enhance research governance practices that may be suitable to be applied in UM.

\section{Methodology}

Three (3) major referred policies and strategic plans were studied and the processes for research management and governance in Malaysia were reviewed. Results were recorded and reported.

Three (3) major referred policies and strategic plans:

1. The 11th Malaysia Plan 2016 - 2020: Anchoring Growth on People. (Economic Planning Unit, 2015)

2. The Malaysia Education Blueprint 2015 - 2025 (Higher Education). (Ministry of Education Malaysia, 2015)

3. The Malaysian Science, Technology \& Innovation (STI) Indicators Report 2016. (Ministry of Science, Technology and Innovation, 2017)

\section{Research and Development Landscape in Malaysia}

Malaysia's research and development landscape has grown tremendously over the last decade. The growth of scholarly output (publication, articles, reviews) in Malaysia has also risen significantly at the rate of 7.2\% compared to countries such as China (4.2\%), Singapore (3.6\%) and Australia (4.6\%) (Figure 1). Malaysia aims to continue increasing research output and quality with $1.3 \%$ of the GDP spent on Research and Development (R\&D). Thus far, Malaysia has achieved phenomenal growth within the research sector, with a four-fold increase in the number of citations and generated approximately RM1.25 billion through 11\% yearly growth in the number of patents from Malaysian Universities. 


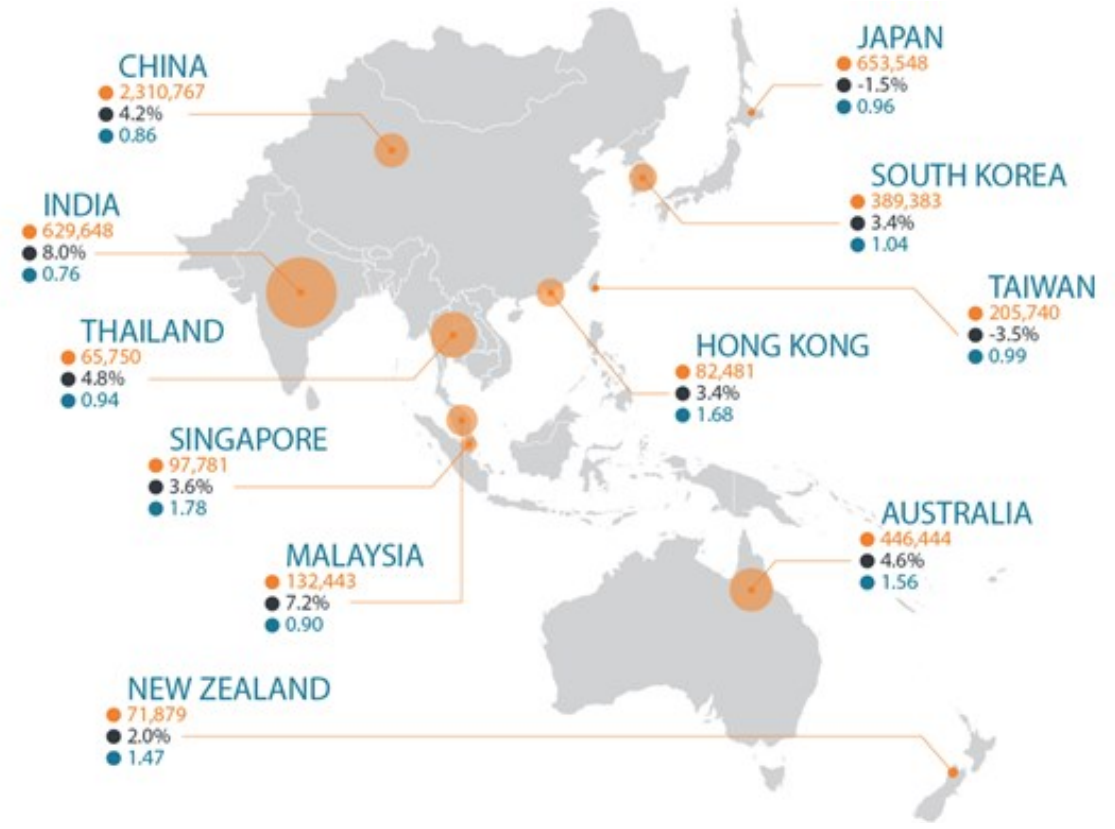

Figure 1: Growth of Scholarly Output in the Asia Pacific Region. (Elsevier, 2018)

Research \& Development (R\&D) activities in Malaysia are carried out by R\&D professionals in three sectors: universities, research institutions and private R\&D companies/industries. Currently, there are 20 public universities and 467 private institutions of higher learning in Malaysia (universities, branch universities, university colleges and colleges).

Expenditure on R\&D by Sectors (2000-2018)

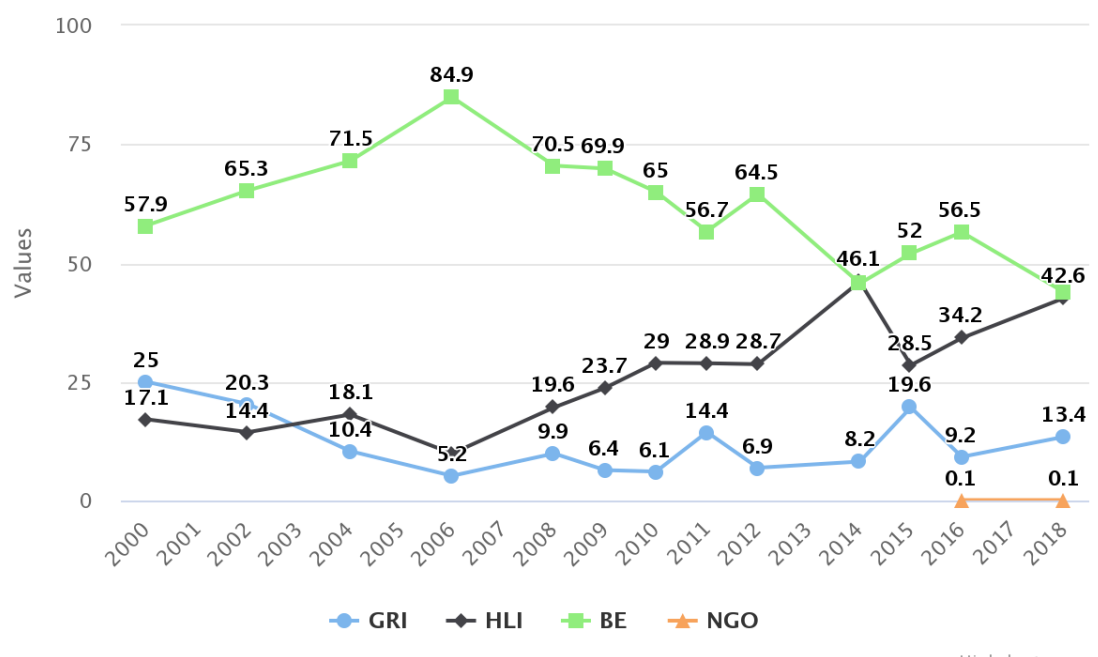

Figure 2: Expenditure on R\&D by Sectors (2000-2018). (MASTIC, 2018) 
Figure 2 shows that the Business Enterprise (BE) sector has remained as the largest contributor to spur of R\&D activities in Malaysia until 2018 . The Business Enterprise (BE) sector is the major exploiter on that year (RM6,614 million, 43.9\%). The second major contributor in R\&D is Higher Learning Institution $(\mathrm{HLI})$, with the value of RM6,412 million (42.6\%). Vice versa, the minor contributor goes to Government Research Institutes (GRI) RM2,019 million (13.4\%) and Non-Governmental Organisation (NGO) RM15 million (0.1\%). The average percentage of funds received by a research university to finance innovations and research activities for the year 2006 to 2011 is also shown in Figure 3.

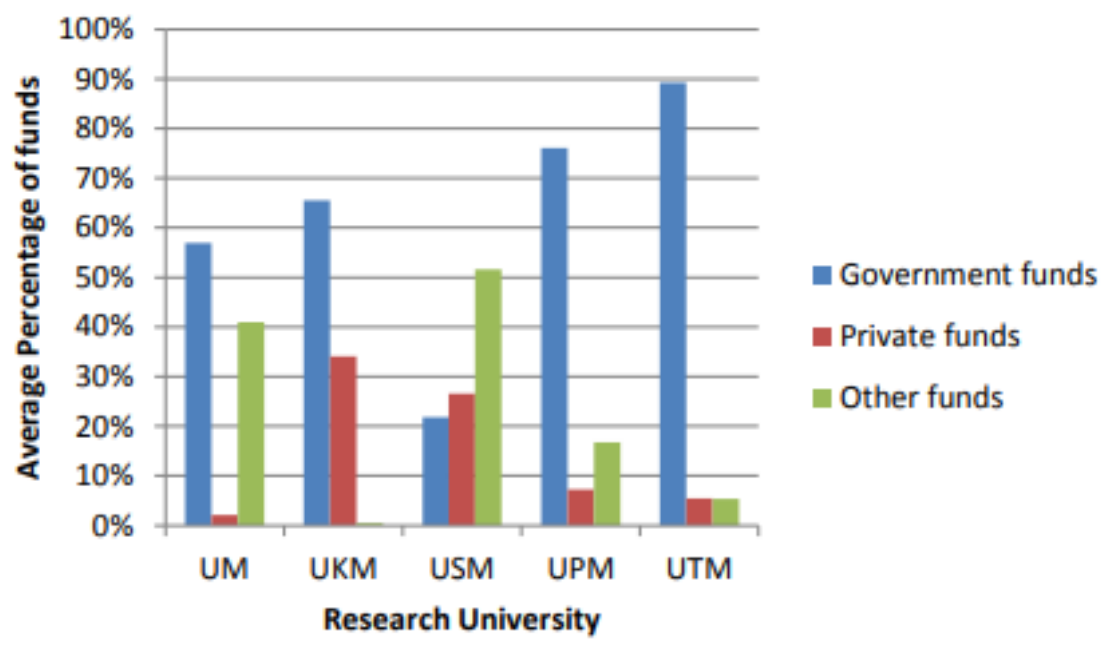

Figure 3: The average percentage of funds received by a research university to finance innovations and research activities for the year 2006 to 2011. (Amran et al., 2014)

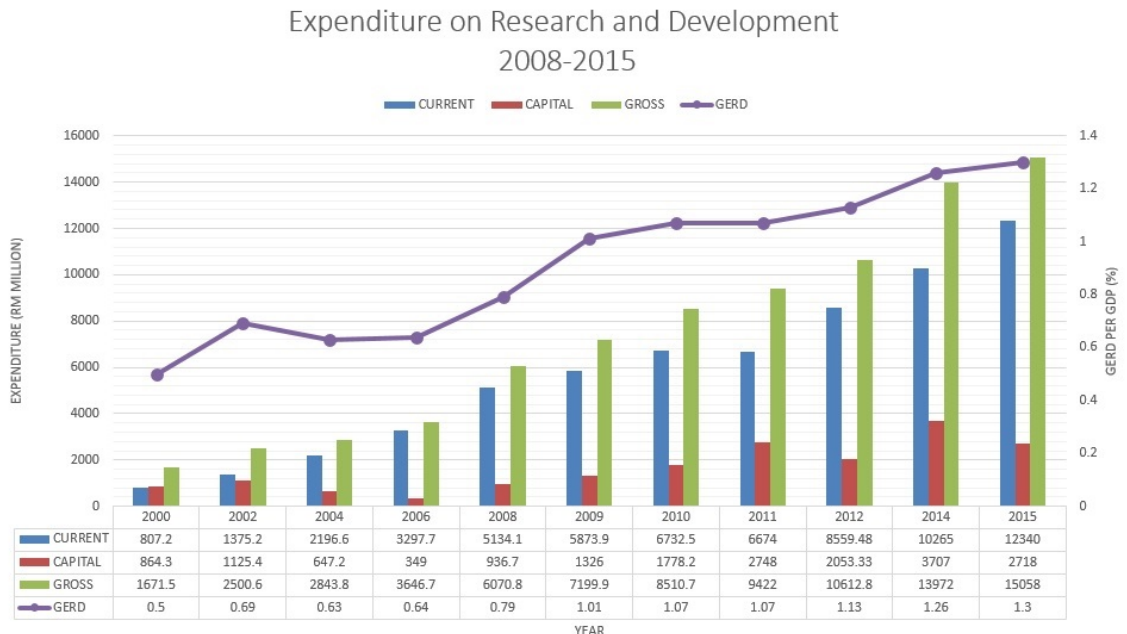

Figure 4: Expenditure on R\&D 2008 - 2015 in Malaysia. (MASTIC, 2018)

Figure 4 shows that the Gross Domestic Expenditure on R\&D (GERD) in Malaysia has been steadily increasing since 2000 . For the fiscal year 2015, Malaysia recorded the highest GERD at RM15,058 million, an increase of $148.04 \%$ over the GERD value in 2008 (RM6,070.8 million). The intensity of R\&D, a 
measure of the percentage of GERD to GDP (GERD/GDP) also shows an increment as the GERD value had continuously increased since 2004. In 2015, the GERD/GDP was $1.30 \%$, an increment of $64.56 \%$ compared to the year $2008(0.79 \%)$.

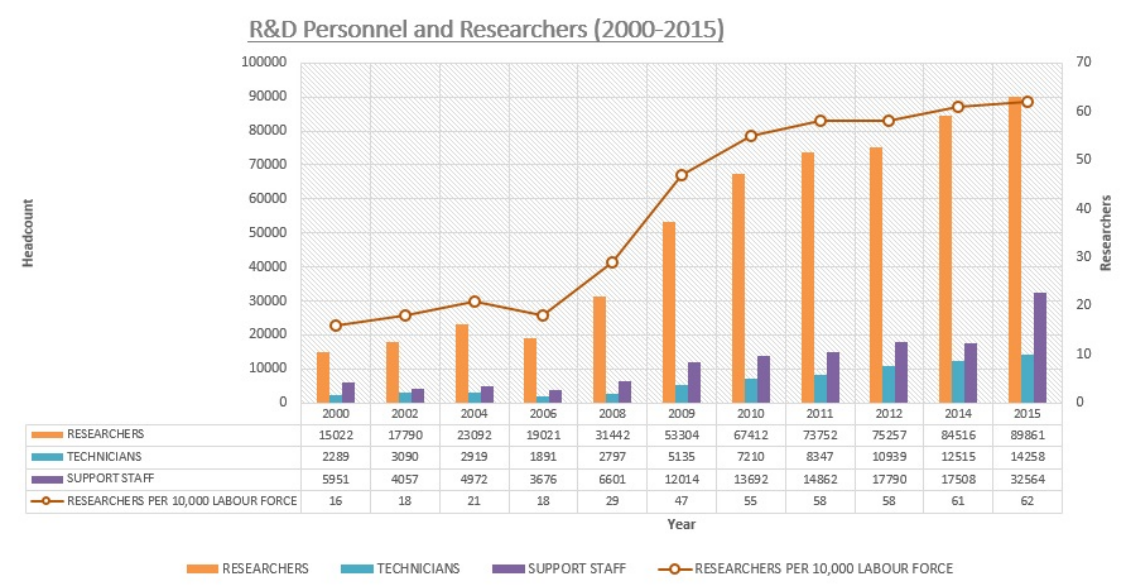

Figure 5: R\&D Personnel and Researchers (2000 - 2015) in Malaysia. (MASTIC, 2018)

Figure 5 shows that the number of active researchers progressively had increased since 2006 . The highest number of researchers was recorded in 2015 , with a total of 89861 , an increase of $185.80 \%$ over the number of researchers in $2008(31,442)$. On the other hand, the number of researchers per 10,000 labour forces in 2015 had also increased to 62 people.

\section{Research Governance}

\subsection{Management and monitoring of research}

Stakeholders from various sectors (Government Agencies, Industrial Partners, International Agencies and Institutions) provide various types of funding and resources to support research in UM. The Deputy Vice Chancellor (Research \& Innovation) is responsible for the overall research agenda in UM. Units under the portfolio manage research grant management in UM and this includes the initiative of seeking funds (in terms of research grants/sponsorship) from respective funding bodies.

Generally, research governance on management and monitoring research process is divided into preaward and post-award processes. Different funding bodies may impose different processes and guidelines depending on the objectives of the funding given. The pre-award process involves several steps such as the announcement of funding, evaluation of proposed projects internally at the institutional level, evaluation by funding bodies and followed by awarding grants. Meanwhile, at the post -award phase, research activities are monitored at the respective institutional level. Monitoring of research project performance at the institutional level is done through desktop monitoring. Funding bodies may conduct different monitoring activities to assess the performance of projects. Another aspect of monitoring projects is the financial project report. All principal investigators or project leaders have to report their financial expenditure to ensure that the use of the grant awarded is in line with what has been proposed in the proposal. Some funders may request the project leaders to present the outcome and results after the project duration has ended. 
In UM, the protocols and procedures in research grant management are divided into pre-award and post -award. There are various units involved directly and indirectly in the research governance of UM. Major units involved include the office of the Deputy Vice-Chancellor (Research \& Innovation), Institute of Research Management \& Services (IPPP), Research Clusters, Centre for Research Grant Management (PPGP) and Centre for Research Services (PPP). At the pre-award level, all internal funds are evaluated at either the central or faculty level while for external funds, the central level collates and verifies the application. At the post-award level, researchers are responsible for their research activities and expenses related to their research activities from application to process related to payment and this is managed by their respective department or faculty.

\subsection{Research funding}

Public R\&D funding and programmes indicate the commitment of the Malaysian government towards strengthening the country's overall scientific and innovation performance. The R\&D funding programmes are designed and implemented by various ministries and agencies to support R\&D activities at different stages; (a) pre-R\&D or the stage of ideation; (b) research stage; (c) development stage; and (d) commercialisation stage. Examples of such funds are tabulated below in Figure 6:

\begin{tabular}{|c|c|c|}
\hline Stage & Name of Fund & Ministry / Agency \\
\hline Pre R\&D & $\begin{array}{l}\text { 1. Cradle Investment Program Catalyst - Seed } \\
\text { 2. Cradle Investment Program Catalyst - Pre Seed } \\
\text { 3. Cradle Seed Venture Fund } 1\end{array}$ & $\begin{array}{l}\text { Ministry of Finance; } \\
\text { Cradle Fund Sdn Bhd. }\end{array}$ \\
\hline Research & $\begin{array}{l}\text { 1. Sciencefund } \\
\text { 2. Fundamental Research Grant Scheme } \\
\text { 3. Long Term Research Grant Scheme } \\
\text { 4. Transdisciplinary Research Grant Scheme } \\
\text { 5. Prototype Research Grant Scheme } \\
\text { 6. Research Acculturation Collaborative Effort }\end{array}$ & $\begin{array}{l}\text { Ministry of Energy, Science, Technology, } \\
\text { Environment \& Climate Change; } \\
\text { Ministry of Education. }\end{array}$ \\
\hline $\begin{array}{l}\text { Development / Pre- } \\
\text { Commercialisation }\end{array}$ & $\begin{array}{l}\text { Techno Fund } \\
\text { InnoFund }\end{array}$ & $\begin{array}{l}\text { Ministry of Energy, Science, Technology, } \\
\text { Environment \& Climate Change. }\end{array}$ \\
\hline Commercialisation & $\begin{array}{l}\text { Commercialisation of R\&D Fund } \\
\text { Technology Acquisition Fund } \\
\text { Biotechnology Commercialisation Fund }\end{array}$ & $\begin{array}{l}\text { Ministry of Energy, Science, Technology, } \\
\text { Environment \& Climate Change; } \\
\text { Malaysian Technology Development } \\
\text { Corporation Sdn Bhd. }\end{array}$ \\
\hline
\end{tabular}

Figure 6: Examples of available research funding in Malaysia

Some universities also provide internal research funding for researchers. In UM, this type of research funding is made available for basic, applied and interdisciplinary research. The process of awarding grants is either at central (PPGP \& Research Cluster) or at faculty level i.e., Research Management Unit (RMU) depending on the research grants offered.

There are also other private/industry funding besides public R\&D funding offered by the Malaysian government and the requirements, assessment and criteria/selection process of these private/industry funding differ according to the grant provider.

\subsection{Support services for research}

The Government of Malaysia provides support services for research to ensure that research activities are conducted in a conducive ecosystem. There are policies and institutions established to focus on high 
quality research and to support the R\&D based on industry demands. For example, the National Institute of Biotechnology (NIBM) under the Ministry of Science, Technology and Innovation (MOSTI), is established to support and spearhead the commercialization of activities of R\&D. In line with Malaysia's biotechnology agenda through activities, research, development, innovation and commercialization, three national biotechnology agencies are also established: Malaysia Agro-Biotechnology Institute (ABI), Malaysia Institute of Pharmaceuticals and Nutraceuticals (IPHARM) and Malaysia Genome Institute (MGI). Another example of government support for research is the Nuclear Malaysia Agency that provides facilities through the establishment and development of important laboratories that can support the needs in nuclear science and technology, hence playing a significant and important role in the national development programme.

At the institutional level, the research support and services given vary according to the available resources and different cohort of researchers. In UM, different kinds of support are given to different target groups, for example, UM academics will be given opportunities to attend training, conferences, symposiums to improve skills in teaching and research. Training on Massive Open Online Courses (MOOCs) and Open Educational Resources (OER), training for academic staff; EMERALD (Early career researcher), INSPIRE (continuous professional development) and LEADER are other examples. As for students, research modules are designed to assist skills development among postgraduate students on research methodology, proposal defence, candidature defence and thesis defence.

\subsection{Role of leadership in research development}

Universities in Malaysia are given the autonomy to plan their research directions and implement their research governance. However, it is encouraged that this is done in alignment with the policies and strategies of the Ministry of Higher Education. The Institute of Higher Education Excellence Planning Division is a unit under the Ministry of Higher Education that has a mission to drive excellence amongst institution of higher learnings through research development and commercialisation, producing talents and competitive research outcomes at the national and international level. This division works closely with the Research Management Unit of various institutions.

In UM, there are four Deputy Vice-Chancellors who answer directly to the Vice-Chancellor, one of whom is in charge of research and innovation - Deputy Vice-Chancellor (Research \& Innovation). The DVC (R\&I) is responsible for the overall research agenda in UM. The DVC is also responsible for formulating the strategic planning and research direction of the university.

The DVC (R\&I) is currently assisted by two Associate Vice-Chancellors (AVCs): i) Industry and Community Engagement (ICE), and ii) Research \& Innovation (R\&I).

i. AVC (ICE) is assisted by three Directors; UM Centre of Innovation \& Commercialization (UMCIC), University of Malaya Consultancy Unit (UPUM) and The Community \& Sustainability Centre of UM (UMCARES).

ii. AVC (R\&I) also acts as the Director of the Institute of Research Management \& Services (IPPP). The AVC (R\&I) administration is further assisted by four (4) Deans of Research Clusters, Head of Research Data Management Unit (RDMU), Research Management Policy and Strategy Unit (UDSI), 
Centre of Research Grant Management (PPGP), Centre for Research Services (PPP) and Data Intensive Computing Center (DICC).

UM's levels of research management can be categorized as: i) Central level - Centre of Research Grant Management (PPGP) and Research Clusters; and ii) Faculty Level - Research Management Unit (RMU). However, not all faculties at UM have an RMU.

\subsection{Research performance, benchmarking and portfolio}

MyRA, the Malaysian Research Assessment, is a comprehensive instrument developed to assess the research capacity and performance of all universities in Malaysia. It was introduced in 2009 by Ministry of Higher Education Malaysia as an instrument to assess the performance of the Research Universities $(R U)$. Four public universities were granted the RU status, namely Universiti Malaya (UM), Universiti Kebangsaan Malaysia (UKM), Universiti Putra Malaysia (UPM), and Universiti Sains Malaysia (USM), followed by Universiti Teknologi Malaysia (UTM) that joined the fraternity of RUs in 2010.

MyRA has set well-established standards which serve as benchmarks for aspiring universities such as Universiti Utara Malaysia to join the ranks of the present RUs. MyRA includes a 6-Star rating system and all participating universities are document-audited and site-audited by a panel comprising trained auditors. Malaysian research universities are among the top $1 \%$ in the world (out of 26,000 universities worldwide) based on the QS World University Rankings 2016/2017 and 2017/2018 (Star Online, 2017).

Subsequently, the assessment tool, MyRA, evolved into MyRA I and MyRA II in 2012 whereby different weightage is allocated for different sections of the assessment, as illustrated in Figure 7. While MyRA II is designed for research universities, non-research universities are also mandated to complete the assessment as stipulated in MyRA I. Moving forward, the focus of RUs and non-research universities is on the translational research approach, research that brings positive impact to local and international communities. Translational research programmes must be linked to the Government Transformation Programme.
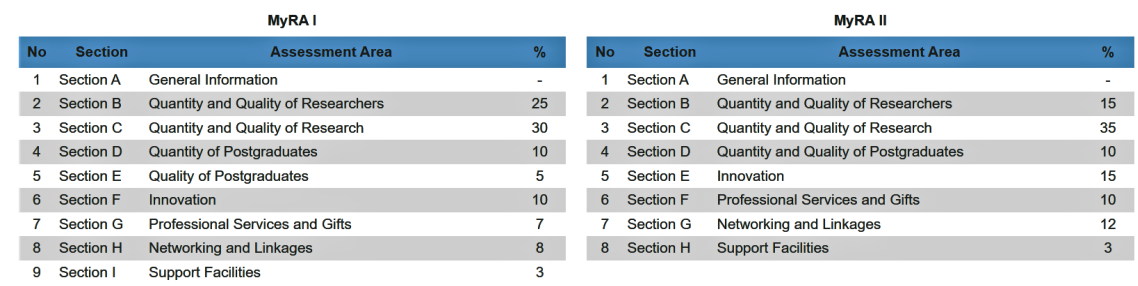

Figure 7: MyRA I and MyRA II Criteria. (Universiti Sains Malaysia, 2021) 


\subsection{The wider focus of research - bridging the academic with the industry, society and transnational boundaries}

Research in Malaysia has widened its research focus by bridging academics with industry and society at the national and international level. There are initiatives in place linking researchers and relevant partners. One of the initiatives spearheaded by the Ministry of Higher Education Malaysia, the DemandDriven Project by the Public-Private Research Network (PPRN), is aimed to address the technological knowledge gaps and provide a platform through research between universities, industries and society.

Malaysian researchers are also encouraged to translate laboratory-scale research to contribute towards productivity and the nation's economic growth. This has attracted stakeholders such as micro, small and medium enterprises and associations (government and non-government) to be in partnership with researchers. The Malaysian Government supported this initiative by providing funds for these purposes as described in Figure 5.

UM has established centres, under the purview of the portfolio of research and innovation to link the UM researchers with external stakeholders, namely the UM Centre of Innovation \& Commercialization (UMCIC), which acts as a centralised technology transfer and commercialization unit, the University of Malaya Consultancy Unit (UPUM) which specialises in undertaking joint venture works with industries and government sectors, and the Community \& Sustainability Centre of UM (UMCARES) which focuses on community engagement and acts as the university community transformation centre (UCTC), bridging researchers to society through various programmes.

As Malaysia is moving towards the fully developed country status, it is important to inculcate the spirit of working together and across discipline amongst our expert to address real problems faced by our society and producing real-world impact. Thus, taking into consideration the potential impact of interdisciplinary research in aiding the acceleration of scientific discovery in innovative ways, UM has taken the initiatives by providing specific grants for interdisciplinary research with the aim to address real-world issues relevant to society and industry.

\subsection{Diversity, innovation and sustainability in research}

The 11th Malaysia Plan 2016-2020 has, as its focus, people wellbeing and prosperity of the people. The Plan is also in the final leg in the journey towards realising Vision 2020 to achieve full development in Malaysia. Productivity and innovation are basic pillars of the Plan, which are based on six Strategic Thrusts, i) Enhancing inclusiveness towards an equitable society; ii) Improving wellbeing for all; iii) Accelerating human capital development for an advanced nation; iv) Pursuing green growth for sustainability and resilience; v) Strengthening infrastructure to support economic expansion, and vi) Reengineering economic growth for greater prosperity.

In the enhanced innovation ecosystem, it is envisaged that there will be greater collaboration and integration across industry, academia and communities. Research will be closely aligned with industry demand and the private sector will be active partners in research and development, and commercialisation and innovation (R\&D and C\&I) by contributing funds, expertise and other resources 
for greater return on investment. Communities will also be actively engaged with the researchers in addressing the social issues through a "whole of society" approach as social innovation is an essential process for the evolution of society and the search for sustainable alternatives. Furthermore, it adds an extra dimension to innovation, sustaining economic and social growth.

\section{Recommendations to Enhancing Research Mechanisms and Institutional Processes in Malaysia}

Malaysia's research output as shown in Figure 8 can be considered significant based on the number of publications published in high impact journals and the increase in citations. However, some local universities lack positive engagement with policymakers, especially in the sharing of data/findings for the policy-making process, and it would be an advantage for universities to learn strategies and best practices for successful engagement with policymakers from other successful universities abroad.

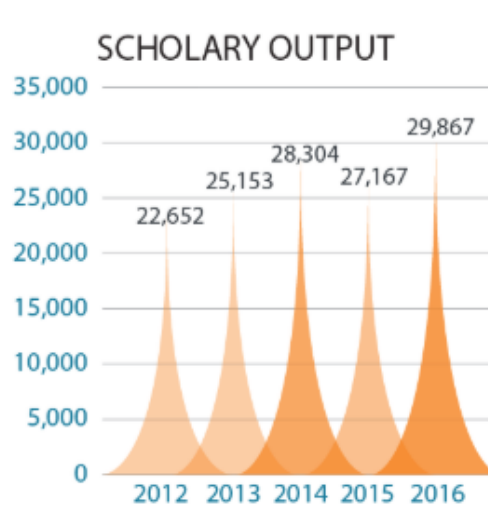

\section{PUBLICATIONS INTOP $10 \%$ JOURNAL} PERCENTILES BY CITESCORE (2012 - 2016)

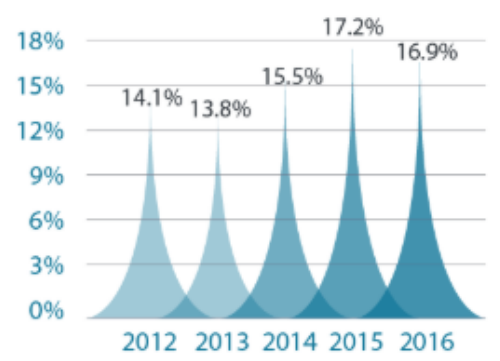

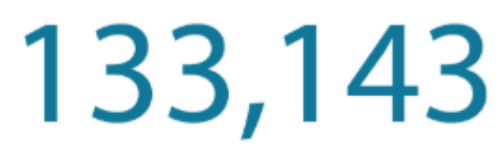

NUMBER OF PUBLICATIONS BY MALAYSIAN INSTITUTIONS (2012-2016)

\section{PUBLICATIONS IN TOP 1\% JOURNAL PERCENTILES BY CITESCORE (2012 - 2016)}

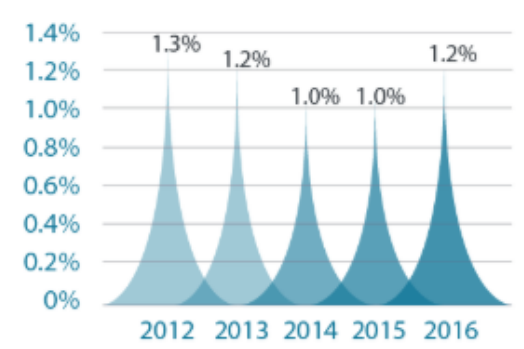

Figure 8: Number of publications by Malaysia Institutions (2012 - 2016). (Elsevier, 2018)

The current research management framework at Malaysian universities has been in place since the 7th Malaysia Plan. The typical structure involves functions organised under the university research management centre. Academics are seconded from their lecturer positions to head the centre and lead the functions. This Malaysia model poses pros and cons. The one biggest advantage of the model is the 
level of understanding of the academics in the research processes. However, with academics allocating time to manage research, time for research and teaching is reduced. This could bring significant consequences to the individual's research development as well as the university outputs and achievements.

Compared to the Malaysian model, and from what is being practiced in some European, American or even East Asian universities (taking the University of Groningen as an example), professionals are hired for research management. This might be one good solution towards reducing the massive workload of Malaysian academics at the research management centre. UM, as an example, has started to adopt this concept a few years ago. However, it is still at the learning stage since research management is a special field that may not be supported as much by contemporary management theories but by the strength of the management and continuous evolving theories and expertise through experience. Thus, professional development such as training on specific skills and exposure of the professionals to best practices in the different regions and/or countries is important. Discussions and sharing of best practices in managing research by other international universities with the local universities would benefit Malaysian universities at large.

Towards the end of the study, the project has a wider objective which is to develop human capital and facilitate individual learning and institutional mechanisms in Social Science research through research training and capacity building, including research governance, leading to sustainable high-quality research, conditions for cooperation and potential for policy impact. Recommendations to improve the current mechanism/practices of research management and governance in the university have also been proposed to UM's management for further consideration and implementation:

a) Strategy I - Ensure that the environment in UM supports the conduct of research to the highest standards, and the governance of research management and mechanisms are in its highest efficiency and effectiveness.

b) Strategy II - Focus on building research excellence by creating and supporting next generation of research leaders/world-leading clusters of researchers, building on the research strengths of UM and harnessing the capacity that had been developed within the University's research environment over the previous 15 years (after UM being recognized as RU in year 2006).

c) Strategy III - Enhance the sustainability of the significant levels of research supports (grants, facilities, database etc.)

To read more on the strategies and action plans related to the proposed strategies, readers may refer to the "Pre-Seminar DEV2 - Building The Social Research Capacities In Higher Education Institutions In Lao PDR and Malaysia (BRECIL) Report" funded by Erasmus+ CBHE [Project number: 585852-EPP-1-2017-1MY-EPPKA2-CBHE-JP].

\section{Conclusion}

Malaysia has, as one of its goals, to be the regional education hub. Thus, the creation of a vibrant research and innovation ecosystem is crucial for research universities to strive for as well as to be the preferred global research partner. To measure the achievements, a more qualitative-oriented performance assessment must be done comprehensively. Malaysia is encouraged to explore a different 
method and criteria for evaluating the fulfilment of the strategy and benchmarking it with the leading universities. In addition, strengthening the methods for identification and landscaping of the industries' needs and the potential collaboration with the researchers at universities is imperative. For example, UM has engaged with various industries, however, the current outcomes need to be enhanced to achieve a win-win situation for both parties.

Research outcomes should impact the society. Therefore, the effectiveness of societal engagement programmes and initiatives should be evaluated. UM has tried to adopt methods from the Manual of Community Capacity Index (University of Queensland, Australia, 2002), however, its implementation in the Malaysian setting has been challenging. Thus, suggestions to overcome the challenges and/or alternative evaluation methods would be valuable.

\section{Acknowledgements:}

Erasmus+ CBHE "Building Social Research Capacity in Higher Education Institution in Lao PDR and Malaysia" (BRECIL) [Project number: 585852-EPP-1-2017-1-MY-EPPKA2-CBHE-JP].

\section{Disclaimer:}

This communication reflects the views only of the author(s), and the Commission cannot be held responsible for any use which may be made of the information contained therein.

\section{References:}

Amran, F.H., Abdul Rahman, I.K., Salleh, K., Syed Ahmad, S.N. \& Haron, N.H. (2014). Funding trends of research universities in Malaysia. Procedia - Social and Behavioral Sciences, 164(2014), 126 - 134. doi: 10.1016/j.sbspro.2014.11.060

Azirah Hashim, Yee, C.L. \& Azman Firdaus, A.N.F. (2018). Empowering the Academic Community with Knowledge and Skills in ELT and Education-Based Research: Capacity Building in Selected Public and Private Higher Education Institutions in Cambodia and Laos. In Abdul Rahman, S. \& Shuib, M. (eds), Success Stories of Malaysia's Global Reach and CLMV Programs. KL, Malaysia: IIUM Press.

Economic Planning Unit. (2015). The $11^{\text {th }}$ Malaysia Plan 2016 - 2020: Anchoring Growth on People. Retrieved at https://www.pmo.gov.my/dokumenattached/RMK/RMKe-11Book.pdf

Elsevier. (2018). Research Excellence and Beyond - In an age of globalization, will the Asian academic emergence continue in countries like Malaysia and beyond? Retrieved from https:// www.elsevier.com/research-intelligence/campaigns/malaysia-research-excellence-and-beyond

Ministry of Science, Technology and Innovation (2017). Malaysian Science, Technology \& Innovation (STI) Indicators Report 2016. Retrieved at https://mastic.mosti.gov.my/sti-survey-content-spds/ malaysian-science-technology-innovation-sti-indicators-report-2016

Normaniza, O., Abdul-Rahman, P. S., \& Rahim, H. R. (2020). Research Landscape in Universiti Malaya: Fostering Interdisciplinary Research Culture. Kuala Lumpur: Unpublished. 
Star Online. (June 8, 2017). Five Malaysian public research varsities listed in top $1 \%$ universities worldwide. Retrieved from https://www.thestar.com.my/news/nation/2017/06/08/malaysianuniversities-surge-in-world-rankings/

Universiti Malaya. (2021a). Universiti Malaya Official Web. Retrieved from https://um.edu.my/

Universiti Malaya. (2021b). UM International Relations Office Official Web. Retrieved from https:// international.um.edu.my/mou-moa

Universiti Sains Malaysia. (2021). MyRA I \& MyRA II Criteria. Retrieved from https://www.kpims.usm.my/ $\underline{\mathrm{v} 2 / ? \mathrm{p}=\text { myra-criteria }}$ 